\title{
Evidence for a pre-malignant cell line in a skin biopsy from a patient with Nijmegen breakage syndrome
}

\author{
Raneem Habib ${ }^{1,2}$, Heidemarie Neitzel ${ }^{2}$, Aurelie Ernst ${ }^{3}$, John K. L. Wong ${ }^{3}$, Bozenna Goryluk-Kozakiewicz ${ }^{4}$,
} Antje Gerlach², Ilja Demuth ${ }^{5}$, Karl Sperling ${ }^{2^{*}+}$ (I) and Krystyna Chrzanowska ${ }^{4 \dagger}$

\begin{abstract}
Background: Nijmegen breakage syndrome is an autosomal recessive disorder characterized by microcephaly, immunodeficiency, hypersensitivity to X-irradiation, and a high predisposition to cancer. Nibrin, the product of the NBN gene, is part of the MRE11/RAD50 (MRN) complex that is involved in the repair of DNA double strand breaks (DSBs), and plays a critical role in the processing of DSBs in immune gene rearrangements, telomere maintenance, and meiotic recombination. NBS skin fibroblasts grow slowly in culture and enter early into senescence.

Case presentation: Here we present an incidental finding. Skin fibroblasts, derived from a 9 year old NBS patient, showed a mosaic of normal diploid cells $(46, X Y)$ and those with a complex, unbalanced translocation. The aberrant karyotype was analysed by G-banding, comparative genomic hybridization, and whole chromosome painting. The exact breakpoints of the derivative chromosome were mapped by whole genome sequencing: 45,XY,der(6)(6pter $\rightarrow$ $6 q 11.1: 13 q 11 \rightarrow 13 q 21.33:: 20 q 11.22 \rightarrow 20 q$ ter), 13 . The deleted region of chromosomes 6 harbors almost 1.400 and that of chromosome 13 more than 500 genes, the duplicated region of chromosome 20 contains about 700 genes. Such unbalanced translocations are regularly incompatible with cellular survival, except in malignant cells. The aberrant cells, however, showed a high proliferation potential and could even be clonally expanded. Telomere length was significantly reduced, hTERT was not expressed. The cells underwent about 50 population doublings until they entered into senescence. The chromosomal preparation performed shortly before senescence showed telomere fusions, premature centromere divisions, endoreduplications and tetraploid cells, isochromatid breaks and a variety of marker chromosomes. Inspection of the site of skin biopsy 18 years later, presented no evidence for abnormal growth.
\end{abstract}

Conclusions: The aberrant cells had a significant selective advantage in vitro. It is therefore tempting to speculate that this highly unbalanced translocation could be a primary driver of cancer cell growth.

Keywords: Nijmegen breakage syndrome, Cell line, Unbalanced translocation, Proliferative advantage

\section{Background}

Nijmegen breakage syndrome (NBS) is an autosomal recessive disorder characterized by chromosome instability associated with microcephaly, immunodeficiency, hypersensitivity to X-irradiation, and a high predisposition to cancer. The majority of NBS patients are of Central and Eastern European origin and carry the common founder

\footnotetext{
* Correspondence: karl.sperling@charite.de

${ }^{\dagger}$ Equal contributors

${ }^{2}$ Institute of Medical and Human Genetics, Charité - Universitaetsmedizin

Berlin, Berlin, Germany

Full list of author information is available at the end of the article
}

mutation in the NBN (NBS1) gene, c.657_661del5 [1-3]. By the age of 20 years more than $40 \%$ of patients have developed a malignant disease, predominantly of lymphoid origin [4-6]. Even heterozygous carriers of the founder mutation have an increased cancer risk [7, 8]. Nibrin, the product of the $N B N$ gene, is part of the MRE11/RAD50 (MRN) complex that is involved in the repair of DNA double strand breaks (DSBs), both by homologous recombination repair (HRR) and nonhomologous end-joining (NHEJ). Moreover, the NBN gene plays a critical role in the processing of DSBs in 
immune gene rearrangements, telomere maintenance, and meiotic recombination [9-11]. Thus, almost all aspects of the DNA damage response (DDR), including apoptosis, are affected [12].

NBS skin fibroblasts grow slowly in culture and enter early into senescence. Consequently, they have a low reprogramming efficiency into induced pluripotent stem cells (iPSCs) [13]. The iPSCs show, amongst others, numerous chromosomal aberrations, a delayed response to DSB induction, slower growth rate, and a reduced apoptotic response to stress [14].

Here we present a, perhaps unique, incidental finding. Skin fibroblasts, derived from a 9 years old NBS patient showed a mosaic of normal diploid cells and those with a complex, unbalanced translocation, leading to the loss and duplication of hundreds of genes. Such primary events are regularly incompatible with cellular survival. Unexpectedly, these cells showed a high proliferation potential in vitro and could even be cloned. Thus, this complex aberration might represent an early (first) step toward malignant transformation.

\section{Case presentation}

The skin biopsy was obtained from a 9 years old Polish child with NBS. He presented all phenotypic characteristics of NBS, i.e. microcephaly and typical facial features, recurring pulmonary infections, bronchiectasis, and combined humoral and cellular immunodeficiency. The cell line was established with the ethical approval of The Children's Memorial Health Institute, Warsaw. At the age of 21 years the patient underwent total thyroidectomy (papillary thyroid carcinoma, follicular variant).
The patient was under systematic longitudinal observation and treatment at The Children's Memorial Health Institute from the age of 9 until 21 years. The patient was contacted again at the age of 27 years. There was only a scar at the site of the skin biopsy without any evidence of abnormal growth.

\section{Results}

The fibroblast cell line (94P0496) was derived from the NBS patient, homozygous for the common founder mutation in the $N B N$ gene, a five-base-pair deletion, c.657 661del5 in exon 6, that leads to two truncated protein fragments, p26- and p70 Nibrin. After chromosome analysis two cell lines could be identified, one with a normal diploid karyotype, 46,XY, the other with 45 chromosomes. The latter had only one chromosome 6 and 13 plus a derivative chromosome (Fig. 1).

As shown by whole chromosome painting (WCP) the p-arm including the centromere of the derivative chromosome is from chromosome 6, the proximal part of the long arm from chromosome 13 to which the qarm of chromosome 20 is attached, resulting in partial monosomy of chromosome 6 and 13 and partial trisomy of chromosome 20 (Fig. 2). This was confirmed by comparative genomic hybridization (CGH, Fig. 2).

The exact breakpoints were mapped by whole genome sequencing (WGS; Additional file 1: Figure S1a,b). The breakpoint on the derivative chromosome 6 is on $6 \mathrm{q}$ at chr6:63,015,229. Attached to this breakpoint is a chromosome 13-specific satellite I DNA, mapped to chromosome 13 in $13 \mathrm{p} 13$ and the pericentromeric
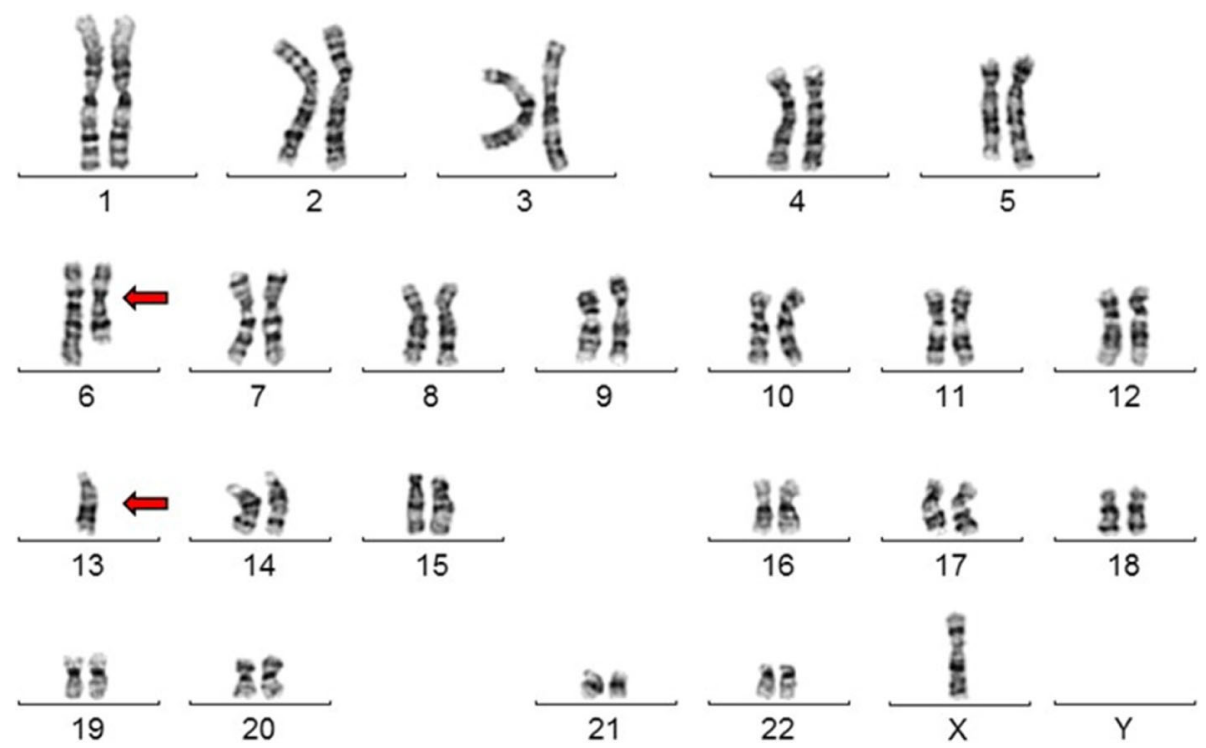

Fig. 1 Karyotype of the aberrant NBS line 94P0496 after G-banding. The arrows point to the derivate chromosome and the one chromosome 13. The chromosomal preparation was performed after cloning, i.e. after about 40 cell divisions. The $Y$ chromosome has been lost during cultivation 

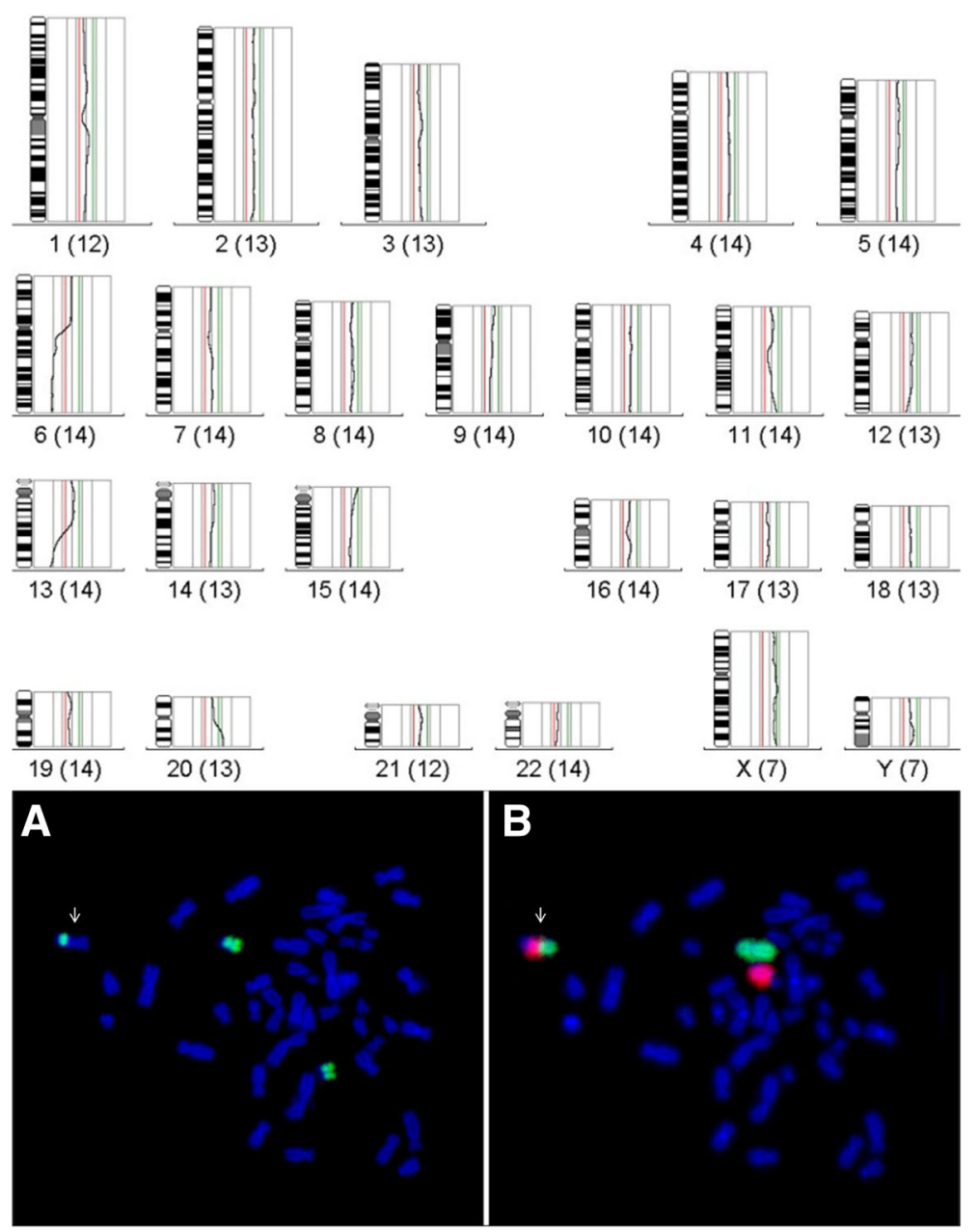

Fig. 2 Characterization of the aberrant line 94P0496 after comparative genomic hybridization and whole chromosome painting. Above: CGH analysis of the aberrant cell line 94P0496 showing partial monosomy for the q arms of chromosome 6 and 13 and partial trisomy for chromosome 20. Below: Metaphase with marker chromosome (white arrow) after whole chromosome painting. A: chromosome 20 in green; B: chromosomes 13 in red and 6 in green (Original from [16])

region [15]. The distal breakpoint on chromosome 13 is at chr13:71,189,298 followed by the translocated segment of the q-arm of chromosome 20 starting at position chr20:34,287,131 to 20qter. Based on FISH analysis with the XL acro-p probe and G-banding there was no evidence for an interstitial short arm of chromosome 13. Thus, we assume that the break was in the subcentromeric band at 13q1.1. The karyotype of this complex unbalanced translocation according to ISCN is: 45,XY,der(6)(6pter $\rightarrow$ 6q11.1::13q11 $\rightarrow$ 13q21.33::20q11.2 $2 \rightarrow 20$ qter),-13. The deleted region of chromosome 6 harbors 1.397 genes, the deleted region of chromosome 13 contains 543 genes, and the duplicated region of chromosome 20 encompasses 710 genes (Fig. 3). Such unbalanced translocations are regularly incompatible with cellular survival, except in malignant cells.

The cell cycle length was analysed after BrdU labelling for 36 and $72 \mathrm{~h}$. Based on the labelling pattern of the sister chromatids (Additional file 1: Figure S2), the diploid and aberrant cells were classified if they had passed one, two or three S-phases after labelling (Table 1). The number of M2 cells after $36 \mathrm{~h}$ and of M3 cells after $72 \mathrm{~h}$ was significantly higher for the aberrant cells and consequently their cell cycle was shorter than that of the diploid cells $(P<0.05)$.

The cells were classified if they had passed one (M1), two (M2) or three S-phases (M3) after labelling. The aberrant cells underwent significantly more cell divisions than those with the normal karyotype (Fisher's exact test, $P<0.05$; Original from [16]).

At an early passage the diploid and aberrant cells were analysed for chromosomal aberrations after irradiation in G2-phase with $0 \mathrm{~Gy}, 0.5 \mathrm{~Gy}$ and $1.0 \mathrm{~Gy}$. About 20 normal and 40 aberrant cells were analysed each. The types of aberrations were classified as achromatic lesions, chromatid and isochromatid 


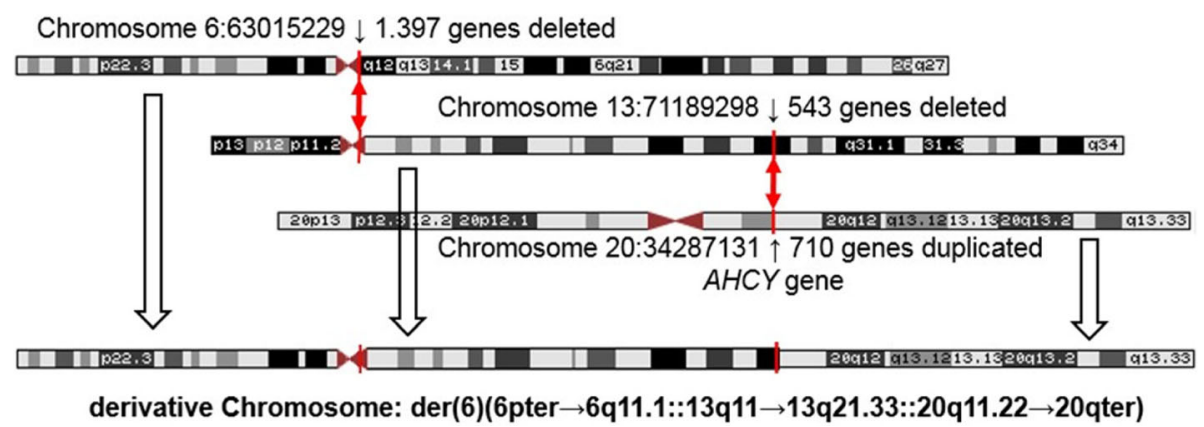

Fig. 3 Reconstruction of the derivative chromosome after whole genome sequencing. The exact breakpoints are depicted and the number of deleted and duplicated genes indicated (NCBI, Map Viewer, Annotation Release 108)

breaks, and chromatid translocation (Additional file 1: Figure S3). In order to calculate the total number of chromatid breaks per cell the latter were counted twice, the achromatic lesions neglected. The number of chromosomal aberrations was significantly higher in the aberrant cells than in the normal ones after irradiation $(P<0.05$; Table 2$)$. Thus, chromosomal instability of the aberrant line was not decreased but increased.

The aberrant cells showed more aberrations than those with the normal diploid karyotype (Chi-square test, $P<0.05$; Original from [16]).

Moreover, telomere length ( $\mathrm{T} / \mathrm{C}$ value) was measured by Q-FISH in 94P0496 and two other NBS fibroblast lines in comparison with 2 control fibroblast cell lines at passage 7 . The telomere length was significantly longer in the controls than in the NBSfibroblasts $(P<0.05)$ with median values $(\mathrm{T} / \mathrm{C}$ values $)$ of 87.9 and 87.5 for the controls and 48.5 for 94P0496 (Fig. 4). Thus, the T/C value of 94P0496 was reduced to about $55 \%$. In addition, the absolute telomere length was measured by Terminal Restriction Fragment (TRF) analysis. This technique is based on Southern blots and also included the subtelomeric region. The NBS fibroblasts had a telomere length of about $12.5 \mathrm{~kb}$ compared to about $17 \mathrm{~kb}$ for the control fibroblast [16]. There was no detectable hTERT expression in the NBS cell line 94P0496 in contrast

Table 1 Analysis of metaphases of the 94P0496 cell line after 36 and $72 \mathrm{~h}$ of BrdU labelling

\begin{tabular}{lllll}
\hline $\begin{array}{l}\text { BrdU } \\
\text { incubation }\end{array}$ & $\begin{array}{l}\text { Mitoses after BrdU } \\
\text { labelling }\end{array}$ & $\begin{array}{l}\text { Metaphases } \\
\text { analysed }\end{array}$ & $\begin{array}{l}\text { aberrant } \\
\text { karyotype }\end{array}$ & $\begin{array}{l}\text { normal } \\
\text { karyotype }\end{array}$ \\
\hline $36 \mathrm{~h}$ & M1 & 5 & 3 & 2 \\
& M2 & 50 & 48 & 2 \\
$72 \mathrm{~h}$ & M1 & 0 & 0 & 0 \\
& M2 & 16 & 13 & 3 \\
& M3 & 34 & 34 & 0 \\
\hline
\end{tabular}

to two SV40 transformed NBS cell lines (Additional file 1: Figure S4).

The cells were cultivated until they reached senescence in two independent culture attempts. Regularly some subcultures were kept confluent for several weeks to test if some cells escaped contact inhibition. This, however, was not the case. In the second attempt, the cells were cloned and fourteen clones propagated. Thirteen clones were diploid, one tetraploid, all contained the derivative chromosome 6 and one normal chromosome 13 (Fig. 1). After confluency the cultures were split at a 1:4 ratio until the cells entered into senescence six to ten passages later. Altogether we calculate that the cells underwent about 50 cell divisions until they reached senescence, i.e. at least ten division after establishment of the cell line from tissue pieces until the cells could be propagated for the first time. After four passages they were cloned. Thereafter, the cells underwent at least 20 cell divisions until the flasks were confluent. After further 12 to 20 cell divisions the cells entered into senescence.

The first chromosomal preparation was performed when the cells were still in logarithmic growth and three G-banded metaphases were analysed each. Only three clones showed in at least two metaphases the original karyotype. The others had additional aberrations, such as telomere fusions and marker chromosomes (Fig. 5). In seven of the 42 metaphases the Y chromosome has been lost. Shortly before the cells entered into senescence the second chromosome preparation was performed. Only in eleven of the fourteen clones some metaphases could be found. All had complex aberrations, such as premature centromere divisions, endoreduplications, tetraploidizations, isochromatid breaks, and a variety of marker chromosomes (Fig. 6).

The examination of the patient 18 years later showed no abnormal growth at the site of the skin biopsy (Fig. 7). 
Table 2 Analysis of chromosomal breaks in normal and aberrant cells of the 94P0496 cell line after irradiation

\begin{tabular}{llllllll}
\hline Dose & 94P0496 cells & Metaphases analysed & Chromatid breaks & Chromatid translocat. & Chromos. breaks & Total Breaks & Breaks/ metaphase \\
\hline 0 Gy & normal & 23 & 5 & - & - & 5 & 0.22 \\
& aberrant & 42 & 10 & - & 2 & 12 & 0.29 \\
0.5 Gy & normal & 20 & 23 & - & 6 & 29 & 1.45 \\
& aberrant & 42 & 53 & 4 & 10 & 66 & 1.57 \\
1.0 Gy & normal & 21 & 39 & - & 13 & 49 & 2.3 \\
& aberrant & 43 & 125 & 6 & 144 & 3.4 \\
\hline
\end{tabular}

\section{Discussion}

The MRN complex is central to the maintenance of genomic stability by the DNA damage response (DDR) network, which is, amongst others, involved in cell cycle checkpoint control, telomere maintenance, and apoptosis. Thus, NBS patients with defective DDR show a highly increased cancer risk due to their massive genetic/chromosomal instability. This leads to a large number of genetically different cells from which those capable of continual proliferation will be selected. Clearly, human tumor cells often show gross chromosomal abnormalities. The question, however, is whether these changes are primary events or secondary epiphenomena reflecting the genomic instability of these cells $[17,18]$. Without any doubt, the growth advantages conveyed by specific chromosomal translocations as in chronic myelogenous leukemia and Burkitt's lymphoma leading to oncogenic fusion proteins or overexpression of oncogenes are primary drivers of cell growth. The prevailing view, however, is that most of the complex chromosomal changes of malignant cells are secondary events. In this context the aberrant NBS fibroblast cell line is of special interest. The percentage of these cells increased during cultivation and they replaced the diploid cells, which is, at least partially,

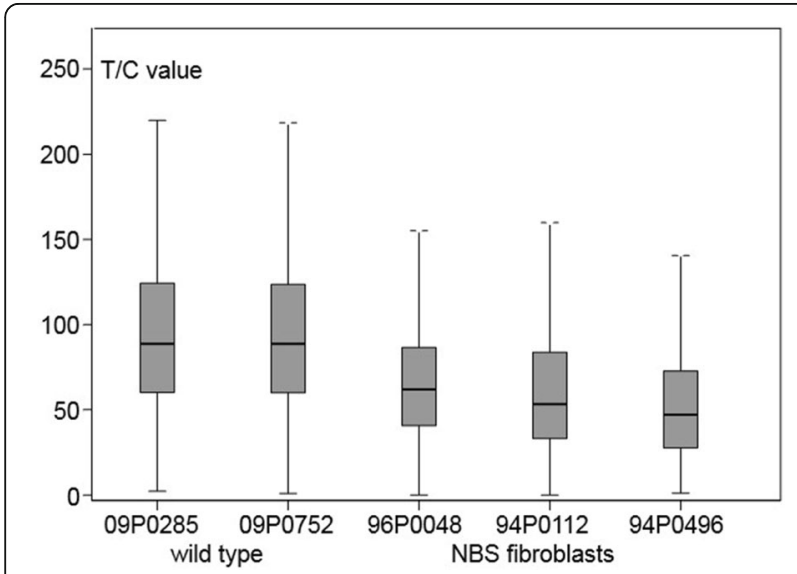

Fig. 4 Boxplots of telomere lengths of normal diploid and NBSfibroblasts. The telomere length (T/C value) of the three NBS cell lines, incl. 94P0496, is significantly shorter than that of the two normal fibroblast cell lines, tested at passage 7 (Mann-Whitney test; $P<0.05$; Original from [16]) explained by its shorter cell cycle. Clearly, this line had a selective advantage in tissue culture, even despite its increased chromosomal instability. Moreover, these cells could be cloned. This is in contrast to NBS skin fibroblasts, which grow slowly in culture, enter early into senescence and have an extremely low reprogramming efficiency [13]. There are strong arguments for the assumption that the derivative chromosome is the crucial, primary event for the selective advantage of this cell line against the NBS background. It was the only cytogenetic aberration detected immediately after establishment of the cell culture. At the third passage after establishment about $50 \%$ of the cells showed the aberrant karyotype, which continuously took over. The derivative chromosome was also present in all 14 clones until senescence.

This complex chromosomal translocation results from the rearrangements between three chromosomes. Such events depend on DNA double-strand breaks and misrepair of the broken chromatin ends [19]. The major DNA repair pathways are Homologous Recombination (HR) and Non-homologous End-Joining (NHEJ) [20]. HR utilizes sister chromatids as a template and is error proof, while the NHEJ process directly ligates the broken DNA ends and is error prone. The flanking sequences of the translocation breakpoints did not show any alterations (see Additional file 1: Figure S1a, b) pointing to HR as possible underlying mechanism.

The telomere length was reduced in the aberrant cell line which is a characteristic of NBS cells in general [21]. Quite surprisingly these cells underwent about 50 cell divisions until they entered into senescence. Telomerase was not expressed, however, we cannot exclude that a telomere maintenance pathway, such as alternative lengthening of telomeres (ALT), was at least temporarily activated. Clearly, the telomeres became shorter during cultivation. The shortened telomere ends are signaled as DSBs leading to telomere fusions and chromosomes with two centromeres in the NBS cells. This results in breakage-fusion-bridge cycles, because the different centromeres may be pulled in opposite directions during anaphase [20]. Thus, the cells acquired numerous additional, non-recurrent chromosomal aberrations apart from those that are due to the inherent chromosomal instability. Interestingly, this took place already during the 


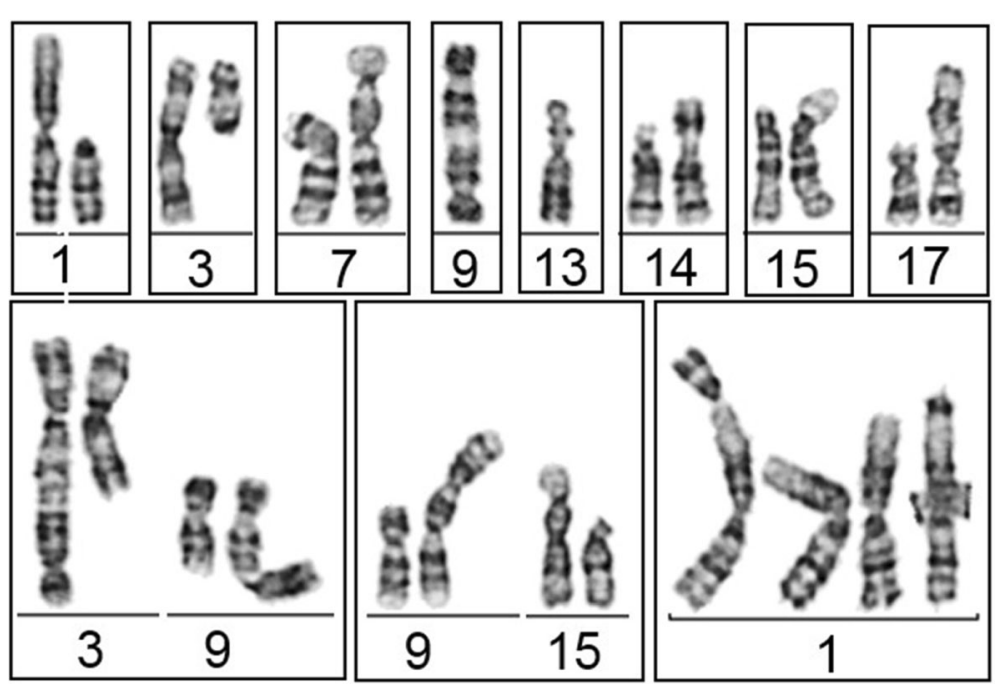

Fig. 5 Pattern of chromosomal aberrations, especially telomere fusions, observed in the aberrant clones during log. growth

phase of logarithmic cell growth (see Fig. 5). In contrast to normal diploid cells, in the aberrant cells the DDR did not trigger the pathway to apoptosis. The impairment of apoptosis and cell cycle checkpoint control is a hallmark of NBS cells in general and was also observed in induced pluripotent stem cells after reprogramming NBS fibroblasts [14]. It could be at least one explanation for the late entry into senescence. However, faced with the enormous imbalance generated by the origin of the

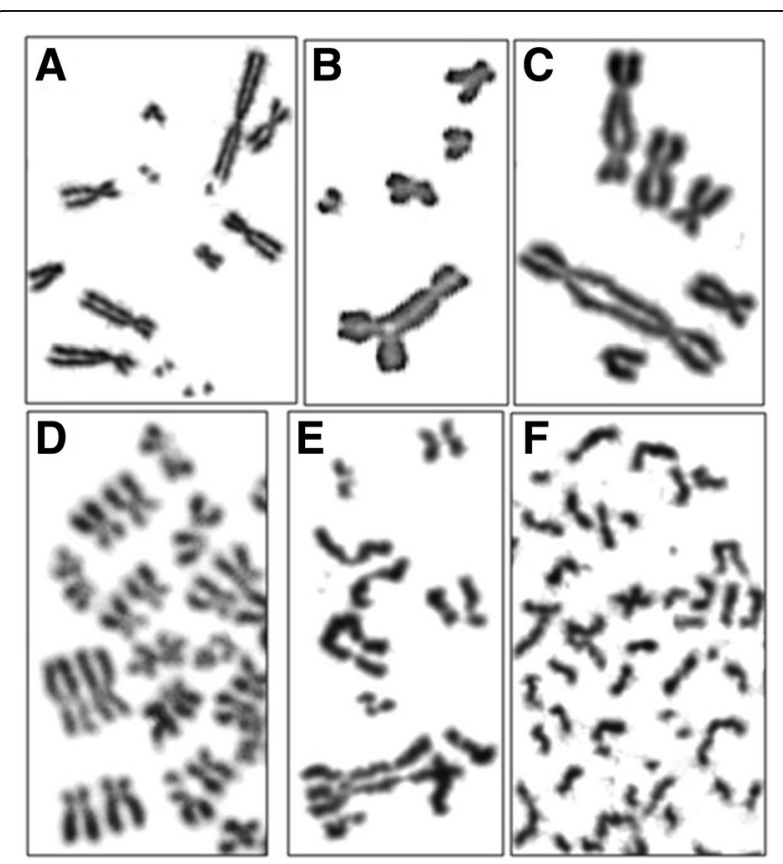

Fig. 6 Pattern of chromosomal aberrations observed in the aberrant clones immediately before entering into senescence. A: multiple isochromatid breaks; B: triradial; C: two dicentric chromosomes (telomere fusion); D: endoreduplication; E and F: premature centromere division derivative chromosome, the observed massive growth advantage is still an open question.

Almost 2.000 genes were lost and 710 genes from chromosome 20 gained. Gain of chromosome 20 is frequently observed in colorectal carcinomas and malignant epithelial tumors [22, 23]. Moreover, the combination of gains of $20 \mathrm{q}$ and losses of $6 \mathrm{q}$ and $13 \mathrm{q}$ is common in oral squamous cell carcinomas [24]. The duplicated 20q region contains the putative oncogenes AURKA and ZNF217, as well as the transcription factor E2F1 that is involved in DSB repair in association with the MRN complex [25]. Loss of the IGF2R on $6 \mathrm{q}$ increases the growth of human and murine tumors [26]. It should be noted that loss of chromosome 14 confers a growth advantage to NBSiPSCs [14]. These few examples, however, only illustrate how gains and losses of specific genes/chromosomes could influence cell proliferation and malignant transformation. In this context it is of interest that a high frequency of spontaneous, nonspecific, and even complex

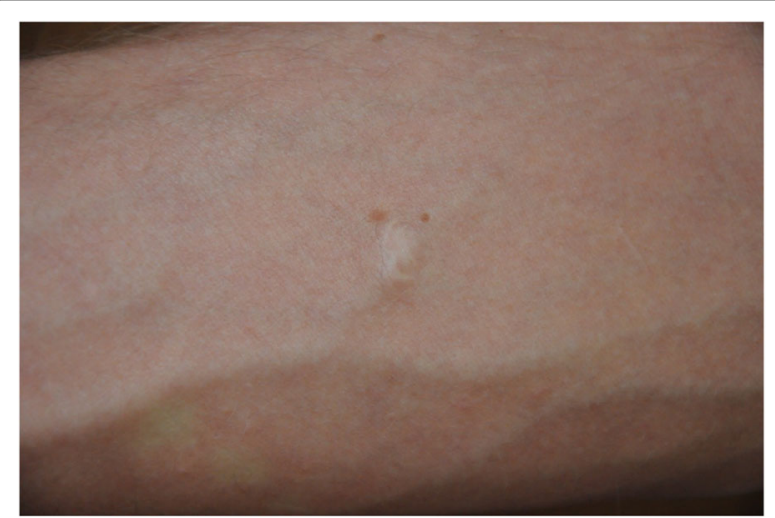

Fig. 7 Scar after skin biopsy 18 years before. There is no evidence for abnormal growth 
translocations were found in lymphocytes and lymphoblastoid cell lines from NBS patients. Moreover, exactly as in our case two clones with such a translocation showed an increased rate of proliferation and the authors pointed out that such clones could serve as an in vitro model for tumorigenesis [27].

\section{Conclusions}

(Partial) aneuploidy of single chromosomes is detrimental to diploid cells, but could be "beneficial" in cancer cells. Most solid cancer show large-scale chromosomal alterations and it is generally accepted that some are functionally important (cancer drivers) whilst others represent only random changes. Based on our findings we come to the conclusion that the derivative chromosome might be a driver aberration and represent an early (first) step in malignant transformation against the NBS background of chromosomal instability. This premise, however, can be tested empirically by reconstitution of telomerase activity in these cells and study if this combination of the derivative chromosome and telomerase confers a tumorigenic phenotype, just in line with the statement of Bunting and Nussenzweig [17] "Making sense of how translocations influence cancer cell growth will be a major topic of research interest in the coming years."

\section{Methods}

\section{Cytogenetics}

The fibroblast were grown and cloned in Amniomax medium at $37{ }^{\circ} \mathrm{C}$ and $5 \% \mathrm{CO}_{2}$, supplemented with the usual amount of antibiotics.

G-banded metaphases were prepared according to standard clinical laboratory procedures. Comparative genomic hybridization $(\mathrm{CGH})$ and whole chromosome painting (WCP) was performed according to Tönnies et al. [28]. Fluorescence in situ hybridization (FISH) was performed with the XL acro-p probe, which specifically hybridize to the p-arms of all human acrocentric chromosomes, according to manufacturer's instruction (MetaSystems). The length of telomeres was measured by quantitative fluorescence in situ hybridization of telomere repeats (Q-FISH) according to Perner et al. [29]. It is based on the fluorescence intensity of single telomeres ( $\mathrm{T})$ relative to a constant repetitive region in the centromeric region of chromosome $2(\mathrm{C})$. The $\mathrm{T} / \mathrm{C}$ ratio reflects the relative length of individual telomeres. In addition, the total relative length of all chromosomes was estimated.

Based on Bromodeoxyuridine labeling (BrdU) for $36 \mathrm{~h}$ and $72 \mathrm{~h}$ the number of cells in the first, second and third mitosis was analyzed after Hoechst 33,258 staining using a florescence microscope (Axioscope) and the software of Metasystems. The number of chromosomal aberrations was calculated $4 \mathrm{~h}$ after $\mathrm{X}$-irradiation with 0.5 and 1.0 Gy (Muller MG $150 \mathrm{X}$ ray apparatus; $\mathrm{U}_{\mathrm{A}}$, $100 \mathrm{kV}$; I, $10 \mathrm{~mA}$; filter, $0.3 \mathrm{~mm} \mathrm{Ni}$; dose rate $2.1 \mathrm{~Gy} /$ min), including $2 \mathrm{~h}$ Colcemid treatment.

\section{Molecular genetics}

The NBN founder mutation was studied by means of exon 6 PCR and sequencing.

Absolute telomere length was measured by Terminal Restriction Fragment (TRF) length analysis, performed according to the standard manufacturer's instruction of Roche (TeloTAGGG telomere length assay). The protocol involved DNA cutting into fragments by a mixture of frequently cutting restriction enzymes: Hinf1 and Rsa1, separating the fragments by gel electrophoresis, and blotting on a nylon membrane. The blotted DNA fragments were hybridized to a digoxigenin (DIG)-labeled probe specific for telomeric repeats, incubated with a DIG-specific antibody, exposed to an $\mathrm{x}$-ray film to estimate the mean TRF length.

Expression of the human telomerase reverse transcriptase gene (hTERT) was analyzed by qPCR. The hTERT CDNA was synthesized according to the standard manufacture's instruction (Invitrogen). GAPDH (glyceraldehyde-3-phosphatedehydrogenase) was used as an internal, HPRT (guanine phosphoribosyl transferase) as endogenous control gene. All PCRs were performed on Applied Biosystem prism 7500 (software DSD V1.2.3). The qPCR products were checked by agarose gel electrophoresis, visualized by UV-transilluminator and photographed.

Detailed protocols of the cytogenetic and molecular genetic methods are presented in Habib, 2012 [16].

Whole genome sequencing was performed using the Illumina X Ten platform. Purified DNA was quantified using the Qubit Broad Range double-stranded DNA assay (Life Technologies, Carlsbad, CA, USA). Genomic DNA was sheared using an S2 Ultrasonicator (Covaris, Woburn, MA, USA). Whole- genome sequencing and library preparations were performed according to the manufacturer's instructions (Illumina, San Diego, CA, USA or NEBNext, NEB). The quality of the libraries was assessed using a Bioanalyzer (Agilent, Stockport, UK).

\section{Statistical tests}

The original data were exported to Excel 2007, GraphPad Prism 5 software and SPSS15.0 software for graphs and boxplots, statistical tests as Mann-Whitney, Fisher's exact and Chi- square test.

\section{Additional file}

Additional file 1: Figure $\mathbf{S 1 a}, \mathbf{b}$. Alignment of the CDNA spanning the breakpoints at chromosomes 6 and 13 and chromosomes 13 and 20 Figure S2. Metaphases of the NBS cell line after BrdU labelling for 36 and 
$72 \mathrm{~h}$. Figure S3. Metaphase of the NBS cell line after irradiation with 1.0 Gy. Figure S4 hTERT expression in diploid NBS-fibroblasts and SV40 transformed NBS cell lines. (DOCX $1.44 \mathrm{mb}$ )

\section{Abbreviations}

BrdU: Bromodeoxyuridine; CGH: Comparative genomic hybridization; DDR: DNA damage response; DSB: DNA double strand break; Gy: Gray; HRR: Homologous recombination repair; iPSCs: Induced pluripotent stem cells; MRN: MRE11/RAD50/NBN; NBS: Nijmegen breakage syndrome; NHEJ: Non-homologous end-joining; Q-FISH: Quantitative fluorescence in situ hybridization; TRF: Terminal restriction fragment; WCP: Whole chromosome painting; WGS: Whole genome sequencing

\section{Acknowledgments}

We acknowledge the proband and his parents for their participation. We thank Prof. Peter Lichter, Dr. Raymonda Varon and Dr. Marc Zapatka for their advices and support. We thank Janina Radszewski for her support in hTERT analysis and Brigitte Schröder for her cytogenetic assistance."

\section{Authors' contribution}

HR characterized the NBS cell line in the framework of her dissertation (Q-FISH, X-ray sensitivity, BrdU labelling). KC took care of the proband, provided together with $B G$ the cell line and performed the primary cytogenetic and molecular diagnostics. AE and JW did WGS and the bioinformatic analysis. ID performed the TRF analysis, AG the CGH and FISH analyses, KS and HN cloned the cells and characterized them cytogenetically. KS drafted the paper and all authors read and accepted the manuscript.

\section{Funding}

R. Habib received a stipend from the Damascus University, Syria; K. Sperling was supported by the Deutsche Forschungsgemeinschaft (Collaborative Research Centre 577, Project B1).

\section{Availability of data and materials}

The relevant data generated or analyzed during this study are included within the article. More details are available on request.

\section{Ethics approval and consent to participate}

The cell line was established with the ethical approval of The Children's Memorial Health Institute, Warsaw and the consent of the proband's parents.

\section{Consent for publication}

All authors declared their consent for publication.

\section{Competing interests}

The authors declare that they have no competing interests

\section{Publisher's Note}

Springer Nature remains neutral with regard to jurisdictional claims in published maps and institutional affiliations.

\footnotetext{
Author details

'Department of Human Genetics, Ruhr-University Bochum, Bochum, Germany. ${ }^{2}$ Institute of Medical and Human Genetics, Charité Universitaetsmedizin Berlin, Berlin, Germany. ${ }^{3}$ Division of Molecular Genetics, German Cancer Research Center (DKFZ), Heidelberg, Germany. ${ }^{4}$ Department of Medical Genetics, The Children's Memorial Health Institute, Warsaw, Poland. ${ }^{5}$ Lipid Clinic at the Interdisciplinary Metabolism Center, Charité Universitaetsmedizin Berlin, Berlin, Germany.
}

\section{Received: 14 December 2017 Accepted: 24 January 2018} Published online: 07 February 2018

\section{References}

1. Varon R, Vissinga C, Platzer M, Cerosaletti KM, Chrzanowska KH, Saar K, et al. Nibrin, a novel DNA double-strand break repair protein, is mutated in Nijmegen breakage syndrome. Cell. 1998;93(3):467-76. PubMed PMID: 9590180
2. Carney JP, Maser RS, Olivares H, Davis EM, Le Beau M, Yates JR 3rd, et al. The hMre11/hRad50 protein complex and Nijmegen breakage syndrome: linkage of double-strand break repair to the cellular DNA damage response. Cell. 1998:93(3):477-86. PubMed PMID: 9590181

3. Seemanova E, Varon R, Vejvalka J, Jarolim P, Seeman P, Chrzanowska KH, et al. The Slavic NBN founder mutation: a role for reproductive fitness. PLoS One. 2016;11(12):e0167984. https://doi.org/10.1371/journal.pone.0167984. PubMed PMID: 27936167; PubMed Central PMCID: PMCPMC5148078

4. Demuth I, Digweed M. The clinical manifestation of a defective response to DNA double-strand breaks as exemplified by Nijmegen breakage syndrome. Oncogene. 2007;26(56):7792-8. https://doi.org/10.1038/sj.onc.1210876. PubMed PMID: 18066092

5. Chrzanowska KH, Gregorek H, Dembowska-Baginska B, Kalina MA, Digweed M. Nijmegen breakage syndrome (NBS). Orphanet J Rare Dis. 2012;7:13. https://doi.org/10.1186/1750-1172-7-13. PubMed PMID: 22373003; PubMed Central PMCID: PMCPMC3314554

6. Varon R, Demuth I, Chrzanowska KH. Nijmegen Breakage Syndrome. In: Adam MP, Ardinger HH, Pagon RA, Wallace SE, LJH B, Mefford HC, et al., editors. GeneReviews(R). Seattle: University of Washington; 1993-2018.

7. Seemanova E, Jarolim P, Seeman P, Varon R, Digweed M, Swift M, et al. Cancer risk of heterozygotes with the NBN founder mutation. J Natl Cancer Inst. 2007;99(24):1875-80. https://doi.org/10.1093/jnci/djm251. PubMed PMID: 18073374

8. Gao P, Ma N, Li M, Tian QB, Liu DW. Functional variants in NBS1 and cancer risk: evidence from a meta-analysis of 60 publications with 111 individual studies. Mutagenesis. 2013;28(6):683-97. https://doi.org/10.1093/mutage/ get048. PubMed PMID: 24113799

9. Komatsu K. NBS1 and multiple regulations of DNA damage response. J Radiat Res. 2016;57(Suppl 1):i11-i7. https://doi.org/10.1093/jrr/rrw031. PubMed PMID: 27068998; PubMed Central PMCID: PMCPMC4990113

10. Digweed M, Sperling K. Nijmegen breakage syndrome: clinical manifestation of defective response to DNA double-strand breaks. DNA Repair (Amst). 2004;3(8-9): 1207-17. https://doi.org/10.1016/j.dnarep.2004.03.004. PubMed PMID: 15279809

11. Lamarche BJ, Orazio NI, Weitzman MD. The MRN complex in double-strand break repair and telomere maintenance. FEBS Lett. 2010;584(17):3682-95. https://doi.org/10.1016/j.febslet.2010.07.029. PubMed PMID: 20655309; PubMed Central PMCID: PMCPMC2946096

12. Stracker $T H$, Petrini $J H$. The MRE11 complex: starting from the ends. Nat Rev Mol Cell Biol. 2011;12(2):90-103. https://doi.org/10.1038/nrm3047. PubMed PMID: 21252998; PubMed Central PMCID: PMCPMC3905242

13. Mlody B, Wruck W, Martins S, Sperling K, Adjaye J. Nijmegen breakage syndrome fibroblasts and iPSCs: cellular models for uncovering diseaseassociated signaling pathways and establishing a screening platform for antioxidants. Sci Rep. 2017;7(1):7516. https://doi.org/10.1038/s41598-017-07905-2. PubMed PMID: 28790359; PubMed Central PMCID: PMCPMC5548734

14. Halevy T, Akov S, Bohndorf M, Mlody B, Adjaye J, Benvenisty N, et al. Chromosomal instability and molecular defects in induced Pluripotent stem cells from Nijmegen breakage syndrome patients. Cell Rep. 2016;16(9):2499511. https://doi.org/10.1016/j.celrep.2016.07.071. PubMed PMID: 27545893

15. Kalitsis P, Earle E, Vissel B, Shaffer LG, Choo KH. A chromosome 13-specific human satellite I DNA subfamily with minor presence on chromosome 21: further studies on Robertsonian translocations. Genomics. 1993;16(1):104-12. https://doi.org/10.1006/geno.1993.1147. PubMed PMID: 8486347

16. Habib R. Analysis of telomere length in patients with chromosomal instability syndromes, particularly Nijmegen breakage syndrome (NBS) and its mouse model by complementary technologies [dissertation]: Free University Berlin; 2012. http://www.diss.fu-berlin.de/diss/receive/FUDISS_ thesis_000000038521?lang=en.

17. Bunting SF, Nussenzweig A. End-joining, translocations and cancer. Nat Rev Cancer. 2013;13(7):443-54. https://doi.org/10.1038/nrc3537. PubMed PMID: 23760025

18. Wang $\mathrm{JH}$. Mechanisms and impacts of chromosomal translocations in cancers. Front Med. 2012;6(3):263-74. https://doi.org/10.1007/s11684-0120215-5. PubMed PMID: 22865120

19. Pellestor F, Anahory T, Lefort G, Puechberty J, Liehr T, Hedon B, et al. Complex chromosomal rearrangements: origin and meiotic behavior. Hum Reprod Update. 2011;17(4):476-94. https://doi.org/10.1093/humupd/dmr010. PubMed PMID: 21486858

20. Shrivastav M, De Haro LP, Nickoloff JA. Regulation of DNA double-strand break repair pathway choice. Cell Res. 2008;18(1):134-47. https://doi.org/10. 1038/cr.2007.111. PubMed PMID: 18157161 
21. Kong CM, Lee XW, Wang X. Telomere shortening in human diseases. FEBS J. 2013;280(14):3180-93. https://doi.org/10.1111/febs.12326. PubMed PMID: 23647631

22. De Angelis PM, Stokke T, Beigi M, Flatberg G, Enger M, Haug K, et al. Chromosomal 20q gain in the DNA diploid component of aneuploid colorectal carcinomas. Int J Cancer. 2007;120(12):2734-8. https://doi.org/10, 1002/ijc.22537. PubMed PMID: 17354231

23. Baudis M. Genomic imbalances in 5918 malignant epithelial tumors: an explorative meta-analysis of chromosomal CGH data. BMC Cancer. 2007;7: 226. https://doi.org/10.1186/1471-2407-7-226. PubMed PMID: 18088415; PubMed Central PMCID: PMCPMC2225423

24. Noutomi Y, Oga A, Uchida K, Okafuji M, Ita M, Kawauchi S, et al. Comparative genomic hybridization reveals genetic progression of oral squamous cell carcinoma from dysplasia via two different tumourigenic pathways. J Pathol. 2006;210(1):67-74. https://doi.org/10.1002/path.2015. PubMed PMID: 16767698

25. Biswas AK, Johnson DG. Transcriptional and nontranscriptional functions of E2F1 in response to DNA damage. Cancer Res. 2012;72(1):13-7. https://doi. org/10.1158/0008-5472.CAN-11-2196. PubMed PMID: 22180494; PubMed Central PMCID: PMCPMC3563329

26. Hoyo C, Murphy SK, Schildkraut JM, Vidal AC, Skaar D, Millikan RC, et al. IGF2R genetic variants, circulating IGF2 concentrations and colon cancer risk in African Americans and whites. Dis Markers. 2012;32(2):133-41. https://doi. org/10.3233/DMA-2011-0865. PubMed PMID: 22377707; PubMed Central PMCID: PMCPMC3751395

27. Stumm M, Neubauer S, Keindorff S, Wegner RD, Wieacker P, Sauer R. High frequency of spontaneous translocations revealed by FISH in cells from patients with the cancer-prone syndromes ataxia telangiectasia and Nijmegen breakage syndrome. Cytogenet Cell Genet. 2001;92(3-4):186-91. https://doi.org/10.1159/000056900. PubMed PMID: 11435685

28. Tonnies H, Stumm M, Wegner RD, Chudoba I, Kalscheuer V, Neitzel H. Comparative genomic hybridization based strategy for the analysis of different chromosome imbalances detected in conventional cytogenetic diagnostics. Cytogenet Cell Genet. 2001;93(3-4):188-94. 56983. PubMed PMID: 11528111

29. Perner S, Bruderlein S, Hasel C, Waibel I, Holdenried A, Ciloglu N, et al. Quantifying telomere lengths of human individual chromosome arms by centromere-calibrated fluorescence in situ hybridization and digital imaging. Am J Pathol. 2003;163(5):1751-6. https://doi.org/10.1016/500029440(10)63534-1. PubMed PMID: 14578175; PubMed Central PMCID: PMCPMC1892442

\section{Submit your next manuscript to BioMed Central and we will help you at every step:}

- We accept pre-submission inquiries

- Our selector tool helps you to find the most relevant journal

- We provide round the clock customer support

- Convenient online submission

- Thorough peer review

- Inclusion in PubMed and all major indexing services

- Maximum visibility for your research

Submit your manuscript at www.biomedcentral.com/submit

) Biomed Central 